\title{
Perennial Symmetry Arguments: Aristotle’s Heavenly Cosmology and Noether's First Theorem
}

\author{
Ryan Miller
}

\begin{abstract}
Attempts to find perennial elements in Aristotle's cosmology are doomed to failure because his distinction of sub- and supra-lunary realms no longer holds. More fruitful approaches to the contemporary importance of Aristotelian cosmology must focus on parities of reasoning rather than content. This paper highlights the striking parallels between Aristotle's use of symmetry arguments in cosmology and instances of Noether's First Theorem in contemporary physics. Both observe simple motion, find symmetries in that motion, argue from those symmetries to notions of conservation, and then conclude to cosmological structure. These parallels reveal an enduring relevance for Aristotelian cosmology that does not depend on positing an enduring content to his cosmological claims.
\end{abstract}

\section{Aristotle's Cosmology, Then and Now}

The physical cosmology of material spheres proposed by Aristotle ${ }^{1}$ has been considered obsolete since "Tycho Brahe's observations of the su-

_ per-nova of 1572." ${ }^{2}$ Natural philosophy shifted quickly from Galileo's view that Aristotle was an arch-enemy to be criticized at every turn to Descartes's treatment of the Stagirite as a vanquished opponent rarely worthy of comment. ${ }^{3}$ Now metaphysical neo-Aristotelianism is booming though severed from cosmology, ${ }^{4}$ while the small minority who see contemporary relevance for Aristotelian cosmology have mainly pursued a dubious double strategy. First they search for terms in contemporary cosmology which will perform the roles required by Aristotle, e.g., a first motion whose measure can be "the objective and intrinsic first time by which all motions and times must be measured." Second, they cast doubt on the validity of terms from contemporary cosmology which do not easily cohere with Aristotle, e.g., inertia. ${ }^{6}$ Both arms of this strategy are dubious because Aristotelian cosmology is founded on a bifurcation of supra-lunary and sub-lunary realms, ${ }^{7}$ whereas the "remarkable discovery" grounding modern astronomy "is that the stars are made of atoms of the same kind as those on the earth." Aristotle's Phainomena are not our 
phenomena, so the terms of their explanations do not exhibit direct concord or discord: they are parts of different systems. ${ }^{9}$ This study therefore follows William Wallace's pioneering work on Galileo in seeking not perennial terms but rather perennial relations,$^{10}$ examining the parity of reasoning between Aristotle's symmetry arguments in the De Caelo and contemporary applications of Noether's First Theorem (that every differentiable symmetry of a physical system's evolution implies a conservation law $\left.{ }^{11}\right)$. First I will examine the arguments from directed motion to its causes, second those running from symmetric motion to conservation, and third those concluding from conservation to claims about cosmology.

\section{Observing Directed Motion}

\subsection{Simple Motion and Natural Place in Aristotle}

Aristotle begins De Caelo I.2 by observing that there are simple motions "away from or towards or about the center," 12 and to each correspond "simple bodies. . . which possess a principle of movement in their own nature." 13 Because Aristotle takes the efficient, formal, and final causes of natural motion to be coincident, ${ }^{14}$ he concludes that what "produces upward and downward movement is that which produces weight and lightness, and that which is moved is that which is potentially heavy and light, and the movement of each body to its own place is motion towards its own form." 15 W. D. Ross interprets this passage to mean that "The proper place of a body, according to Aristotle, has an actual influence on it; an attractive influence which draws the body to it, as the form which matter is destined to assume has an attractive influence on matter." 16 The attractive influence of form, for Ross, is almost like Newtonian gravity, an attractive force emanating at a distance from the destination, which is the cause of the force as separated from the body acted upon. ${ }^{17}$ This interpretation, however, suffers from two grave difficulties. First, Aristotle is explicit that the principle of natural motion is not extrinsic to the moving body: "the simple bodies (earth, fire, air, water) ... exist by nature ... each of them has within itself a principle of motion and of stationariness ... which seems to indicate that nature is a principle or cause of being moved and of being at rest in that to which it belongs primarily, in virtue of itself and not accidentally." ${ }^{18}$ If the simple body is not yet in its natural place, then that place is not a principle of motion within the simple body, and motion caused by it would be violent rather than natural. Second, Aristotle defines "the place of a thing" as "the innermost motionless boundary of what contains it" and infers that "place is coincident with the thing, for boundaries are coincident with the bounded." ${ }^{19}$ A simple body's natural place does not strictly exist, then, in the absence of that simple body, and so cannot be the actual source of

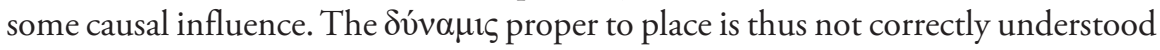
as the power, influence, or capacity of an existing place but rather as place having a certain potentiality. ${ }^{20}$ Ross's interpretation imports to Aristotle both Giordano Bruno's anti-Aristotelian ambivalence about distinguishing natural and violent motions and his replacement of 'place' with the pre-existing receptacle of 'space. ${ }^{.21}$ Read on 
his own terms, Aristotle does presuppose a center for the cosmos, but he attributes simple motion relative to that center to the natures of the simple bodies themselves.

\subsection{Fundamental Particles and Fields in 20th Century Physics}

In contrast to Aristotle's assumption that the earth occupies the unique center of the universe, modern cosmology assumes as its unproven foundation "the Copernican Principle-that we live at a typical position in the universe." ${ }^{22}$ More technically, "relativity postulates that the metrical structure is the only intrinsic spatio-temporal structure and that, more specifically, nothing intrinsic to space-time picks out a preferred reference frame. ${ }^{23}$ This metrical structure is in practice equivalent to the stress-energy tensor, ${ }^{24}$ which in turn is "evaluated according to the solutions of the equations of motion." ${ }^{25}$ Richard Feynman helpfully explains why physicists have adopted this seemingly tendentious and indirect way of speaking:

[Because] the analysis of forces of the more fundamental kinds. . .[is] very much more complicated than is indicated by the inverse-square laws and these laws hold true only when the interacting bodies are standing still, an improved method is needed to deal with the very complex forces that ensue when the bodies start to move in a complicated way. Experience has shown that an approach known as the concept of a "field" is of great utility for the analysis of forces of this type. . The point is to divide the analysis into two parts. One part says that something produces a field. The other part says that something is acted on by the field. By allowing us to look at the two parts independently, this separation of the analysis simplifies the calculation of a problem in many situations. ${ }^{26}$

Feynman then defines field as "any physical quantity which takes on different values at different points in space." ${ }^{27}$ On the one hand, these fields are nothing over and above the natural powers of the fundamental particles, which are simple bodies. ${ }^{28}$ On the other hand,

In spite of how it might at first seem, this separation of [fields from particles] is not a triviality. It would be trivial, just another way of writing the same thing, if the laws of force were simple, but the laws of force are so complicated that it turns out that the fields have a reality that is almost independent of the objects which create them. One can do something like shake a charge and produce an effect, a field, at a distance; if one then stops moving the charge, the field keeps track of all the past, because the interaction between two particles is not instantaneous. It is desirable to have some way to remember what happened previously. If the force upon some charge depends upon where another charge was yesterday, which it does, then we need machinery to keep track of what went on yesterday, and that is the character of a field. So when the forces get more 
complicated, the field becomes more and more real, and this technique becomes less and less of an artificial separation. ${ }^{29}$

So for instance, with regard to electromagnetism,

The natural interpretation of electrical interaction is that two objects simply attract each other: plus against minus. However, this was discovered to be an inadequate idea to represent it. A more adequate representation of the situation is to say that the existence of the positive charge, in some sense, distorts, or creates a "condition" in space, so that when we put the negative charge in, it feels a force. This potentiality for producing a force is called an electric field. When we put an electron in an electric field, we say it is "pulled." We then have two rules: (a) charges make a field, and (b) charges in fields have forces on them and move.

No place in the field is special, except as determined by the trajectories of the charges. The motion of the charges is simple relative to the field, merely following the gradient, which can be made precise by saying that "The true field is the one, of all those coming from the gradient of a potential, with the minimum total energy," and the mechanical effect is that "the average kinetic energy less the average potential energy is as little as possible for the path of an object going from one point to another." ${ }^{30}$ When this principle of least action holds we can be assured that the motion is natural, following from the potentials acting on the particle according to its nature. When we do not observe the principle of least action there must be a further unaccounted-for field gradient acting on the particle (e.g., gravity on an electron), resulting in complex rather than simple motion.

\subsection{Reasoning about Dimension in Aristotle and 20th Century Physics}

Aristotelian cosmology begins with the assumption of a center, observes simple motions, and then infers simple bodies. Places are important as the termini of the natural motions of those simple bodies. Modern cosmology assumes that places are unimportant, observes simple bodies, and then infers simple motions. Places are only contingently important as the dynamical results of the location and movements of the simple bodies. Despite these differences in assumptions, order, and emphasis, the parity of reasoning is impressive. In both systems the realities are the natures of simple bodies; place is physically relevant only because those natures have dimensive ${ }^{31}$ effects. Nonetheless it is only with respect to a somewhat artificial and reified sense of place (the center or field) that the motion of the simple bodies is actually observed to be simple. 


\section{From Symmetric Motion to Conservation}

\subsection{Aristotle on the Continuous and the Incorruptible}

Aristotle's differentiation of celestial motion is based not only on the direction of the simple motion (about the center), but its time symmetry, or invariance. ${ }^{32}$ Aristotle takes this celestial motion about the center to be a manifestly natural motion because it is totally unimpeded, with no sign of orbital decay. ${ }^{33}$ The simple body which naturally exhibits that simple motion must lack a contrary, else it would be subject to decay. ${ }^{34}$ The reason why the simple body exhibiting celestial motion about the center "can have no contrary" is that "there can be no contrary motion to the circular." ${ }^{35}$ The most promising candidate for a contrary to such motion would seem to be circular motion in the opposite direction, but "nor again can motion along the circle from A to B be regarded as the contrary of motion from A to C; for the motion goes from the same point towards the same point, and contrary motion was distinguished as motion from a contrary to its contrary." ${ }^{36}$ Circular motion about the center, however, is the orbit of the heavens in time, ${ }^{37}$ so this amounts to the claim that circular motion is symmetric with respect to time. Because circular motion is time symmetric, or in Aristotle's verbiage has no contrary, "it 'runs always' for an eternity of time," thus "implying that the primary body is something else beyond earth, fire, air, and water" (which are corrupted by their contraries), and so takes "the name of aether." ${ }^{38}$ A time symmetry of motion has implied a conserved (incorruptible) element. ${ }^{39}$

The motion of the other four elements is not similarly time symmetric. Their movements have contraries: "if the natural motion is upward, it will be fire or air, and if downward, water or earth," 40 "not to infinity but to opposite points." ${ }^{11}$ Motion in the contrary direction is unnatural, "as for instance, is the case with the upward and downward movements, which are natural and unnatural to fire and earth respectively." ${ }^{\$ 2}$ Thus under time symmetry, where fire would move back downward and earth back upward, those motions would be violent rather than equivalent to the original natural motions. In other words, not only the motions but also the natures which give rise to those motions are contrary. ${ }^{43}$ How, then, could fire and earth ever be naturally out of place to begin with, so as to commence their natural motions? The answer Aristotle leaves open is that "it is quite possible for one body to be generated out of another, air for instance out of fire," ${ }^{44}$ and this results in the generated element being out of place. ${ }^{45}$ This is how the power of contrary elements can cause an element to be outside its natural place of rest. ${ }^{46}$ The four elements are not themselves conserved because their natural motions are symmetric only under reversal of both time and elemental quality. ${ }^{47}$ In fact, when Aristotle discusses the reciprocal transformation of the elements at De Generatione et Corruptione II.10, he spells out that such transformation confers circular motion's eternality onto rectilinear motion:

all the other things - the things, I mean, which are reciprocally transformed in virtue of their qualities and their powers, e.g., the simple 
bodies_-imitate circular motion. For when Water is transformed into Air, Air into Fire, and the Fire back into Water, we say the coming-to-be has completed the circle, because it reverts again to the beginning. Hence it is by imitating circular motion that rectilinear motion too is continuous. ${ }^{48}$

It follows, however, that there is another candidate for conservation, "for the matter of contraries is the same" ${ }^{49}$ and "though [the elements] are four there must be a common matter of all—particularly if they pass into one another." ${ }^{50}$ Such unqualified generation requires a primary substratum which "is necessarily outside the sphere of becoming and ceasing to be." ${ }^{51}$ Indeed, persistence is written into Aristotle's very definition of matter. ${ }^{52}$ Again a peculiar symmetry of motion (invariance on time reversal and elemental transformation) yields a (non-quantitative) conservation law, the persistence of matter.

\subsection{Noether's Theorem in 20th Century Physics}

That "conservation laws follow from the symmetry properties of nature" is given in a precise mathematical form for modern physics by Noether's first theorem..$^{53}$ Just as Aristotle's symmetry arguments presume simple natural motions, Noether's theorem presumes the principle of least action. ${ }^{54}$ Whereas Aristotle believed that "earth moves more quickly the nearer it is to the center, and fire the nearer it is to the upper place," ${ }^{55}$ contemporary physicists take it as observationally evident that motion is invariant with respect to linear dimensive translation. ${ }^{56}$ Applying a special case of Noether's theorem, the conclusion is that momentum is conserved..$^{57}$ The argument deriving conservation of energy from temporal symmetry works similarly..$^{58}$ Despite the parity of mathematical reasoning, however, there is nonetheless an important difference between conservation of momentum and conservation of energy. Momentum has precisely two components, mass and the velocity vector, and both are directly calculated in experiments. ${ }^{59}$ Energy is different, as Feynman explains:

What is the analogy of this to the conservation of energy? The most remarkable aspect that must be abstracted from this picture is that there are no [elements] ... we find ourselves calculating more or less abstract things. The analogy has the following points. First, when we are calculating the energy, sometimes some of it leaves the system and goes away, or sometimes some comes in. In order to verify the conservation of energy, we must be careful that we have not put any in or taken any out. Second, the energy has a large number of different forms, and there is a [separate] formula for each one. ... It is important to realize that in physics today, we have no knowledge of what energy is.... It is an abstract thing in that it does not tell us the mechanism or the reasons for the various formulas. ${ }^{60}$

Each form of energy has an associated field, and the point particles/simple bodies which mediate this field alone are its gauge bosons, ${ }^{61}$ but these are not themselves conserved. What is conserved during the unqualified generation and 
corruption of these particles is not knowable in itself, though it must exist since the transformation exhibits time symmetry. This is strikingly similar to Aristotle's analysis of matter, "unknowable in itself," 62 but which "can be known by analogy," 63 and must exist since the transformation of the elements is reciprocal. ${ }^{64}$ As with the kinds of energy, which must be as numerous as the kinds of fields, "the kinds of matter, then must be as numerous as these [simple] bodies, i.e., four," and yet as with energy which is only conserved in abstraction from its kinds, "there must be a common matter of all." 65

\subsection{Inertial Invariance: A 20th Century Development}

It is widely supposed that a third candidate for natural symmetry, the so-called ${ }^{66}$ Galilean invariance of motion with respect to inertial frames, was an important break from the grip of Aristotelianism. ${ }^{67}$ When we investigate this 'Galilean invariance' (traditionally "related to the uniform motion of the center of mass"), ${ }^{68}$ however, "we will be surprised to find that the classical action is not invariant under a Galilean transformation," but rather "the two actions. . .differ by a function that depends only on the coordinates of a given event." ${ }^{69}$ In other words, observers in inertial reference frames will observe results that are not quite symmetric or invariant, but rather differ by a constant. Galilean invariance, and its associated law of conservation of the center of mass, does not actually hold without the additional theoretical machinery of Relativity. ${ }^{70}$

\section{From Conservation to Cosmology}

\subsection{The Natural Order of the Universe in Aristotle}

Aristotle argued that the observed order of the world must be a result of natural motion, because violent and chance motions are not continuous. ${ }^{71} \mathrm{He}$ then supposed that the observed cosmology followed from the process "that earth, being a natural substance, grows by having bits of earth come to their natural place-the center of the universe." ${ }^{\prime 2}$ Again, however, this contrasts with a Newtonian theory of gravity, because for Aristotle the downward motion of earth is not caused by the fact that a great mass of earth is already present at the center, but rather the other way around..$^{73}$ Aristotle can thus entertain the counterfactual that the earth should be somewhere other than the center of the universe, ${ }^{74}$ but "the order of the universe would be destroyed if this were to happen. Such a possibility is not real." 75 The coincidence of centers is not a necessary truth, but it is one presumed by Aristotle's cosmology. ${ }^{76}$ Similarly, since the eternal motion of the heavens is not from one place to its opposite, ${ }^{77}$ but rather the continuous natural motion of a simple body, ${ }^{78}$ it too is complete, ${ }^{79}$ and in a way at rest. ${ }^{80}$ The matter, elements, motions, and rest of the sub- and super-lunary realms are all manifestly unlike each other. 


\subsection{Spacetime Homogeneity and its Limits in 20th Century Physics}

Modern physics also reasons from conservation laws to the order of the universe. As Feynman visualizes dimensive invariance,

If there is a piece of equipment in one place with a certain kind of machinery in it, the same equipment in another place will behave in the same way. Why? Because one machine, when analyzed by Moe, has exactly the same equations as the other one, analyzed by Joe. Since the equations are the same, the phenomena appear the same. So the proof that an apparatus in a new position behaves the same as it did in the old position is the same as the proof that the equations when displaced in space reproduce themselves. ${ }^{81}$

This thought experiment is only coherent, however, if there is some way of separating the machine from the space (or the particle from the field). The effect on the field of the particles which are not part of the experiment must be constant throughout the dimensive translation, and so from conservation of momentum, it follows that space is homogenous. ${ }^{82}$ As with Aristotle's assumption of the coincidence of centers, modern physics does not treat the homogeneity of space as necessary-indeed it is probably false ${ }^{83}$ - yet it must be approximately true ${ }^{84}$ and all the generally used physical equations presume it. ${ }^{85}$ Similar difficulties bedevil the conservation of energy and consequent homogeneity in time-Einstein himself took it so strongly as to demand "a static universe, forcing him to introduce the repulsive cosmological constant." ${ }^{86}$ The best attempts to resolve these problems postulate symmetry breaking in the early universe ${ }^{87}$ and consequently a physics unlike that which models the universe hic et nunc. As with Aristotle's cosmological dualism, the twentieth-century variety is potentially beyond the reach of experiment ${ }^{88}$ leading to charges that it is inherently unscientific. ${ }^{89}$

Conclusion

The parities of reasoning discussed in this paper reveal a pairing of terms:

\begin{tabular}{|l|l|}
\hline Aristotelian Cosmology & $\mathbf{2 0}^{\text {th }}$ Century Physical Cosmology \\
\hline place & Field \\
\hline simple body & fundamental particle \\
\hline simple motion & least action \\
\hline continuous motion & time-invariant motion \\
\hline incorruptible & conserved \\
\hline Matter & Energy \\
\hline
\end{tabular}


Because the phenomena explained by the relations among these terms are not the same, the paired terms do not have equivalent content and what is true of one is not necessarily true of the other. Aristotle makes very different assumptions from those of 20th-century physics and has a radically different understanding of the role of mathematics in physical reasoning — his cosmology is not merely misunderstood, or poised for a return. Nonetheless, the pairings revealed by the striking similarities between Aristotelian and contemporary symmetry arguments can be used to discover further such parallels of reasoning. ${ }^{90}$

University of St. Andrews

\section{Acknowledgments}

I would like to thank Jean De Groot and Thomas Davenport, OP for reading previous drafts of this paper, and Fr. Robert Verrill, OP for his response in Minneapolis — of course all errors remain my own. The paper is dedicated to the memory of Fr. William Augustine Wallace, OP. 


\section{Notes}

1. E. J. Aiton, “Celestial Spheres and Circles," History of Science 19.2 (June 1981): 77. https://doi.org/10.1177/007327538101900201.

2. Ibid., 101. Even those who contest the conventional provenance or reasoning behind the change do not much contest the date, e.g., Edward Rosen, "The Dissolution of the Solid Celestial Spheres," Journal of the History of Ideas 46.1 (January 1985): 13. https:// doi.org/10.2307/2709773.

3. Michael Hoskin, The Cambridge Concise History of Astronomy (Cambridge: Cambridge University Press, 1999), 119.

4. Christopher A. Decaen, "Aristotle's Aether and Contemporary Science," The Thomist 68.3 (2004): 376. https://doi.org/10.1353/tho.2004.0015. Edward Feser insists on this severance at "The Medieval Principle of Motion and the Modern Principle of Inertia," in Proceedings of the Society for Medieval Logic and Metaphysics 1.10 (2012): 9.

5. Antonio Moreno, "Time and Relativity: Some Philosophical Considerations," The Thomist 45.1 (1981): 78. https://doi.org/10.1353/tho.1981.0044. Moreno seems to confuse the speed of light, which is common to all observers.

6. E.g., Antonio Moreno, "The Law of Inertia and the Principle Quidquid movetur ab alio movetur," The Thomist 38 (April 1974): 306-331; Glen Coughlin, "Appendix 10. A Brief Note on Inertia," in Physics, or Natural Hearing, by Aristotle, trans. Glen Coughlin (South Bend, IN: St. Augustine's Press, 2004), 274-277. Such arguments rest on an equivocation, as explained by Feser, "The Medieval Principle of Motion and the Modern Principle of Inertia."

7. Decaen, "Aristotle's Aether and Contemporary Science," 375-376; Hoskin, The Cambridge Concise History of Astronomy, 141.

8. The Feynman Lectures on Physics: Mainly Mechanics, Radiation, and Heat, New Millennium Ed., vol. 1 (Basic Books, 2015), sec. 3.4.

9. Thomas J. McLaughlin, "Nature and Inertia," The Review of Metaphysics 62, no. 2 (May 1, 2008): 259 shows how this applies to the case of inertia.

10. Galileo's Logic of Discovery and Proof: The Background, Content, and Use of His Appropriated Treatises on Aristotle's Posterior Analytics, Boston Studies in the Philosophy of Science 137 (Dordrecht: Springer, 1992), http://link.springer.com/10.1007/978-94-0158040-3. Jean De Groot takes a similar approach in Aristotle's Empiricism: Experience and Mechanics in the Fourth Century BC (Las Vegas: Parmenides Publishing, 2014).

11. Emmy Noether, "Invariante Variationsprobleme," Nachrichten von der Gesellschaft der Wissenschaften zu Göttingen, Mathematisch-Physikalische Klasse, 1918, 235-257; for an overview of the result and its importance, see Steve Nadis, "The Universe According to Emmy Noether," Discover, June 12, 2017. http://discovermagazine.com/2017/june/the-universe-according-to-emmy-noether.

12. "On the Heavens," in Complete Works of Aristotle, ed. Jonathan Barnes, trans. J. L. Stocks, vol. 1, Bollingen 61 (Princeton, NJ: Princeton University Press, 1984), 448; De Caelo, ed. D. J. Allan, Oxford Classical Texts (Oxford: Clarendon Press, 1961), 268b24.

13. Aristotle, "On the Heavens," 441; De Caelo, I.2.268b28. Aristotle gives further arguments that the cause of the motion must be inborn at ibid., III.2.301a21-b19. This 
motion is defining: "to ask why fire moves upward and earth downward is the same as to ask why the healable, when moved and changed qua healable, attains health and not whiteness." "On the Heavens," 507; De Caelo, IV.3.310b16-7. As Aristotle says at Meteorologica, ed. Francis Howard Forbes (Cambridge, MA: Harvard University Press, 1919), IV.12.390a, http://archive.org/details/aristotelismeteo00arisuoft, "each of these elements has an end," and "what a thing is is always determined by its function," even if their functions are "harder to specify by physical inquiry" and "we cannot state their definitions accurately." "Meteorology," in Complete Works of Aristotle, ed. Jonathan Barnes, trans. E. W. Webster, vol. 1, Bollingen 61 (Princeton, NJ: Princeton University Press, 1984), 624.

14. "That which produces local motion and that which is so moved are not fortuitously related." "On the Heavens," 506; De Caelo, IV.3.310a20-31. In the phrasing at Physica, ed. David Ross, Oxford Classical Texts (Oxford: Oxford University Press, 1950), II.7.198a24-6; "the form, the mover, that for the sake of which . . coincide; for the what and that for the sake of which are one, while the primary source of motion is the same in species as these." "Physics," in Complete Works of Aristotle, ed. Jonathan Barnes, trans. R. P. Hardie and R. K. Gaye, vol. 1, Bollingen 61 (Princeton, NJ: Princeton University Press, 1984), 338.

15. "On the Heavens," 506; De Caelo, IV.3.310a31-4.

16. In his line-by-line commentary on Physics IV.1.208b10, but citing De Caelo IV.3.310a33 as parallel support at Physics, ed. David Ross (Oxford: Clarendon Press, 1936), 563; I am indebted to Peter K. Machamer, "Aristotle on Natural Place and Natural Motion,” Isis 6.3 (September 1, 1978): 378. https://doi.org/10.1086/352066 for highlighting Ross's view and outlining the direction of difficulty. Machamer's analysis seems broadly sympatico with the one given by Matthen in "Why Does Earth Move to the Center? An Examination of Some Explanatory Strategies in Aristotle's Cosmology," in New Perspectives on Aristotle's De Caelo, ed. Alan Bowen and Christian Wildberg, Philosophia Antiqua 117 (2009): 119-138. http://booksandjournals.brillonline.com/content/books/10.1163/ ej.9789004173767.i-326.42/.

17. McLaughlin makes the comparison explicit, "Local Motion and the Principle of Inertia: Aquinas, Newtonian Physics, and Relativity," International Philosophical Quarterly 44.2 (2004): 257. https://doi.org/10.5840/ipq20044426.

18. "Physics," 1984, 329; Physica, II.1.192b10-23.

19. Ibid., 361; Physica, IV.4.212a20, 30.

20. "Aristotle clearly attributes to place a potency (dunamin), which however is translated in the quotation as 'influence.' A more literal translation would read: 'it (place) has some potency." Machamer, "Aristotle on Natural Place and Natural Motion," 378.

21. Alexandre Koyre, "Galileo and the Scientific Revolution of the Seventeenth Century," The Philosophical Review 52.4 (July 1943): 341-342. https://doi.org/10.2307/2180668.

22. Chris Clarkson, Bruce Bassett, and Teresa Hui-Ching Lu, "A General Test of the Copernican Principle,” Physical Review Letters 101.1 (July 2, 2008): 011301. https://doi. org/10.1103/PhysRevLett.101.011301.

23. Tim Maudlin, Quantum Non-Locality and Relativity: Metaphysical Intimations of Modern Physics, 3rd ed (Malden, MA: Wiley-Blackwell, 2011), 185.

24. Boris Kosyakov, Introduction to the Classical Theory of Particles and Fields (Berlin: Springer, 2007), 210. 
25. Mark S. Swanson, Classical Field Theory and the Stress-Energy Tensor (San Rafael, CA: Morgan and Claypool Publishers, 2015), sec. 4.7.

26. The Feynman Lectures on Physics, 2015, vol. 1, sec. 12.4.

27. The Feynman Lectures on Physics: Mainly Electromagnetism and Matter, New Millennium Ed., vol. 2 (Basic Books, 2015), sec. 1.2.

28. "The total electric field produced by a number of sources is the vector sum of the electric fields produced by the first source, the second source, and so on." The Feynman Lectures on Physics, 2015, vol. 1, sec. 12.4. These sources for the field are true point particles, or simple bodies, without physical substructure or parts: Stanley J. Brodsky and Sidney D. Drell, "Anomalous Magnetic Moment and Limits on Fermion Substructure," Physical Review D 22.9 (November 1, 1980): 2236-2243. https://doi.org/10.1103/PhysRevD.22.2236.

29. The Feynman Lectures on Physics, 2015, vol. 1, sec. 12.4 .

30. The Feynman Lectures on Physics, 2015, vol. 2, sec. 19.1.

31. I say "dimensive" following Aristotle's usage: "A magnitude if divisible one way is a line, if two ways a surface, and if three a body. Beyond these there is no other magnitude, because the three dimensions are all that there are, and that which is divisible in three directions is divisible in all." Aristotle, "On the Heavens," 447; De Caelo, I.1.268a7-9. The more natural "spatial" is inappropriate for Aristotle: Glen Coughlin, "Some Considerations on Aristotelian Place and Newtonian Space," The Aquinas Review 1.1 (2003): 1-53, and also ambiguous in contemporary physics: Erik Curiel, "On the Existence of Spacetime Structure," The British Journal for the Philosophy of Science 69.2 (June 1, 2018): 447-483. https://doi.org/10.1093/ bjps/axw014. See Tim Maudlin, "Substances and Space-Time: What Aristotle Would Have Said to Einstein," Studies in History and Philosophy of Science Part A 21.4 (December 1990): 531-561. https://doi.org/10.1016/0039-3681(90)90032-4 for more.

32. "a thing is symmetrical if one can subject it to a certain operation and it appears exactly the same after the operation." The Feynman Lectures on Physics, 2015, vol. 1, sec. 11.1.

33. "If, on the other hand, the movement of the rotating bodies about the centre is unnatural, it would be remarkable and indeed quite inconceivable that this movement alone should be continuous and eternal, given that it is unnatural. At any rate the evidence of all other cases goes to show that it is the unnatural which quickest passes away." "On the Heavens," 449; De Caelo, I.2.269b6-10.

34. "Everything that comes to be comes into being from a contrary and some substrate, and passes away likewise in a substrate by the action of a contrary into a contrary . . nature seems justly to have exempted from contraries the body which was to be ungenerated and indestructible." Aristotle, "On the Heavens," 450; De Caelo, I.3.270a13-b5.

35. Aristotle, "On the Heavens," 450; De Caelo, I.3.270a19.

36. Ibid., 451; De Caelo, I.4.271a19-22.

37. Aristotle, De Caelo, I.5.272a16.

38. Aristotle, "On the Heavens," 451; De Caelo, I.3.270b22, 21.

39. This rational reconstruction of Aristotle's argument, like Hankinson's ("Natural, Unnatural, And Preternatural Motions: Contrariety And The Argument For The Elements In De Caelo 1.2-4," in New Perspectives on Aristotle's De Caelo, ed. Alan Bowen and Christian Wildberg, Philosophia Antiqua 117, 2009, 83-118, http://booksandjournals.brillonline. 
com/content/books/10.1163/ej.9789004173767.i-326.42/) does not pretend to account for every argumentative move Aristotle makes.

40. Aristotle, "On the Heavens," 448; De Caelo, I.2.269a16; also "movement in a straight line belongs to simple bodies - fire moving straight upward and earthy bodies straight downward towards the centre." "On the Heavens," 449; De Caelo, I.2.269a25-6.

41. Aristotle, "On the Heavens," 460; De Caelo, I.8.277a21.

42. Ibid., 449; De Caelo, I.2.269a33-4.

43. "If earth must exist, so must fire. For, if one of a pair of contraries naturally exists, the other, if it is really contrary, exists also naturally, and has a nature of its own." Aristotle, "On the Heavens," 473; De Caelo, II.3.286a21-3.

44. Aristotle, "On the Heavens," 494; De Caelo, III.3.302a4.

45. "If an element is outside [its natural place], it must have been brought there by one of two causes: either there was contact action by an external source, wrenching the element into another stratum, or there was a transformation of one element into another, resulting in the generated element's being out of place." Machamer, "Aristotle on Natural Place and Natural Motion,” 382.

46. "With these four elements generation clearly is involved, since none of them can be eternal - for contraries interact with one another and destroy one another." Aristotle, "On the Heavens," 473; De Caelo, II.3.286a30-2. "These considerations serve at the same time to explain what is to some people a puzzle-viz. why the bodies, since each of them is travelling towards its own place, have not become dissevered from one another in the infinite lapse of time. The reason is their reciprocal transformation. For, had each of them persisted in its own place instead of being transformed by its neighbour, they would have got dissevered long ago. They are transformed, however, owing to the motion with its dual character; and because they are transformed, none of them is able to persist in any fixed place." Aristotle, "On Generation and Corruption," in Complete Works of Aristotle, ed. Jonathan Barnes, trans. H. H. Joachim, vol. 1, Bollingen 61 (Princeton, NJ: Princeton University Press, 1984), 552; On Coming-to-Be and Passing-Away (De Generatione et Corruptione), ed. Harold H. Joachim (Oxford: Clarendon Press, 1922), II.10.337a8-14, http://archive.org/details/ oncomingtobepass00arisuoft.

47. "Let us then apply the term 'heavy' to that which naturally moves towards the centre, and 'light' to that which moves naturally away from the centre." Aristotle, "On the Heavens," 449; De Caelo, I.3.269b23-24.

48. “On Generation ...”; De Generatione ..., II.10.337a1-7.

49. Aristotle, "On the Heavens," 473; De Caelo, II.3.286a21-4.

50. Aristotle, "On the Heavens," 509; De Caelo, IV.5.312a30. David Bostock takes this, alongside Physics I.9, Metaphysics Z.3, and On Generation and Corruption II.1.329a24-b6 as one of the canonical passages in which Aristotle unequivocally affirms the doctrine of prime matter. Space, Time, Matter, and Form: Essays on Aristotle’s Physics (Oxford: Oxford University Press, 2006), 18, http://www.oxfordscholarship.com/view/10.1093/0199286868.0 01.0001/acprof-9780199286867. Even on Krizan's highly restricted account, the relationship between symmetry and conservation holds: "Elemental Structure and the Transformation of the Elements in On Generation and Corruption 2.4," Oxford Studies in Ancient Philosophy 45 (2013): 195. 
51. Aristotle, "Physics," 1984, 328; Physica, I.9.192a28.

52. Physica, I.9.192a33. While the problem of substantial transformation that prompts Aristotle to conceptualize matter in Physics I.9 is broader than that of elemental transformation, it is because of elemental transformation that the elements themselves cannot be ultimate matter (I.6.189b2).

53. Jozef Hanc, Slavomir Tuleja, and Martina Hancova, "Symmetries and Conservation Laws: Consequences of Noether's Theorem," American Journal of Physics 72.4 (March 10, 2004): 428. https://doi.org/10.1119/1.1591764.

54. Ibid.; See John Brungardt, "The Principle of Least Action and Our Knowledge of Nature" (First Chilean Conference on the Philosophy of Physics, Santiago, Chile, 2018), https://johngbrungardt.com/2018/11/30/the-principle-of-least-action-chile/ for a more comprehensive analysis of the congruence between simple motion and least action." plainCitation":"Ibid.; See John Brungardt, "The Principle of Least Action and Our Knowledge of Nature" (First Chilean Conference on the Philosophy of Physics, Santiago, Chile, 2018

55. Aristotle, "On the Heavens," 460; De Caelo, I.8.277a29. Of course, contemporary physics, too, would say that particles accelerate along the field gradient, but unlike in a system with a fixed center, the whole field can translate in space.

56. The Feynman Lectures on Physics, 2015, vol. 1, sec. 11.2; Hanc, Tuleja, and Hancova, "Symmetries and Conservation Laws," 430."

57. Hanc, Tuleja, and Hancova, "Symmetries and Conservation Laws," 430-431.

58. Ibid., 431.

59. The Feynman Lectures on Physics, 2015, vol. 1, sec. 11.2.

60. Ibid., vol. 1, sec. 4.1. This distinction between the energy itself and its calculated quantity is clear from Lord Kelvin's initial definition of energy as "a capacity for doing work": Crosbie Smith and M. Norton Wise, Energy and Empire: A Biographical Study of Lord Kelvin (Cambridge University Press, 1989), 492. Furthermore, if the energy were itself a quantity, then it would pass away when the substance it is an accident of passed away, being conserved only numerically and not physically: Aristotle, Physica I.2.185a29-32.

61. David McMahon, Quantum Field Theory Demystified (McGraw Hill Professional, 2008), 12.

62. Aristotle, "Metaphysics," in Complete Works of Aristotle, ed. Jonathan Barnes, trans. W. D. Ross, vol. 2, Bollingen 61 (Princeton, NJ: Princeton University Press, 1984), 1635; Metaphysics, ed. William David Ross, vol. 2 (London: Clarendon Press, 1924), VII.10.1036a8.

63. Aristotle, "Physics," 1984, 326; Physica, I.7.191a9.

64. "The theories that there is something common to all the elements, and that they are reciprocally transformed, are so related that those who accept either are bound to accept the other as well." Aristotle, "On Generation ... ." 547; De Generatione . . . , II.7.16-7.

65. Aristotle, "On the Heavens," 509; De Caelo, IV.5.312a30-1.

66. Alan Chalmers, "Galilean Relativity and Galileo's Relativity," in Correspondence, Invariance and Heuristics, ed. Steven French and Harmke Kamminga, Boston Studies in the Philosophy of Science 148 (Dordrecht: Springer, 1993), 189-205. https://doi. org/10.1007/978-94-017-1185-2_10. 
67. E.g., "For many centuries, people believed that a force was necessary to produce motion, as taught by Aristotle. This suggests what might be called 'Aristotle's law of motion,' that force depends on velocity. However, such a law violates Galilean invariance. There can be no distinguishable difference between being at rest and being in motion at constant velocity." Victor J. Stenger, The Comprehensible Cosmos: Where Do the Laws of Physics Come From? (Prometheus Books, 2006), 61.

68. Hanc, Tuleja, and Hancova, "Symmetries and Conservation Laws," 433.

69. Ibid., 432. Maudlin gives a clear qualitative explanation of this phenomenon: Quantum Non-Locality and Relativity, 60.

70. Hanc, Tuleja, and Hancova, "Symmetries and Conservation Laws," 433.

71. "Disorderly movement means in reality unnatural movement, since the order proper to perceptible things is their nature. And there is also absurdity and impossibility in the notion that the disorderly movement is infinitely continued." "On the Heavens," 493; De Caelo, II.2.301a2-10.

72. Machamer, "Aristotle on Natural Place and Natural Motion," 379; "The natural movement of the earth, part and whole alike, is to the centre of the whole-whence the fact that it is now actually situated at the centre." Aristotle, "On the Heavens," 487; De Caelo, II.14.296b7-8.

73. "It happens, however, that the centre of the earth and of the whole is the same. Thus they do move to the centre of the earth, but accidentally, in virtue of the fact that the earth's centre lies at the centre of the whole." Aristotle, "On the Heavens," 487; De Caelo, II.14.296b14-6. "If a place affected a moving body either in the way that the military leader exerts an attraction on his followers, i.e., by conducting himself in a way that they wish to emulate ... or in the way that a gravitating mass does in Newton's theory, then clearly it would be a final or efficient cause. Aristotle ... implies that place is not like this." Matthen, "Why Does Earth Move to the Center?," 119.

74. "If one were to remove the earth to where the moon now is, the various fragments of earth would each move not towards it but to the place in which it now is." Aristotle, "On the Heavens," 506; De Caelo, IV.3.310b3-4.

75. Machamer, "Aristotle on Natural Place and Natural Motion,” 381.

76. "Aristotle can, and I think does, assume that the center of the earth and the center of the cosmos coincide for purposes of conceiving of the order of the cosmos." Ibid.; "Aristotle's cosmological method is to isolate that set of basic explanatory assumptions which best fits the facts overall; and to this end no part of the system as a whole can properly be considered independently of any other part of it. Ultimately, the account as a whole will be justified as a form of inference to the best explanation." Hankinson, "Natural, Unnatural, And Preternatural Motions: Contrariety And The Argument For The Elements In De Caelo $1.2-4, " 85$.

77. "Nor again can motion along the circle from A to B be regarded as the contrary of motion from A to C." Aristotle, "On the Heavens," 451; De Caelo, I.4.271a19-25.

78. "There must necessarily be some simple body which moves naturally and in virtue of its own nature with a circular movement." Aristotle, "On the Heavens," 448; De Caelo, I.2.269a6. 
79. "The complete is naturally prior to the incomplete, and the circle is a complete thing." Aristotle, "On the Heavens," 449; De Caelo, I.2.269a19.

80. Machamer, "Aristotle on Natural Place and Natural Motion," 379n11.

81. The Feynman Lectures on Physics, 2015, vol. 1, sec. 11.2.

82. "The invariance of the action with respect to translation in space is also called the homogeneity of space, which means that all points in space are equivalent. In other words, it does not matter where an experiment is performed." Hanc, Tuleja, and Hancova, "Symmetries and Conservation Laws,” 431.

83. Shaul Hanany et al., "MAXIMA-1: A Measurement of the Cosmic Microwave Background Anisotropy on Angular Scales of 10'-5," The Astrophysical Journal Letters 545.1 (2000): L5.

84. Ch Eisele, A. Yu Nevsky, and S. Schiller, "Laboratory Test of the Isotropy of Light Propagation at the 10-17 Level," Physical Review Letters 103.9 (2009): 090401.

85. Clarkson, Bassett, and Lu, "A General Test of the Copernican Principle."

86. Ibid.

87. A. D. Linde, "A New Inflationary Universe Scenario: A Possible Solution of the Horizon, Flatness, Homogeneity, Isotropy and Primordial Monopole Problems," Physics Letters B 108.6 (February 4, 1982): 389. https://doi.org/10.1016/0370-2693(82)91219-9.

88. T. Goldman and D. A. Ross, "Mass Scales for Grand Unified Theories: Are There Testable Alternatives to SU(5)?," Nuclear Physics B 162.1 (January 7, 1980): 102. https:// doi.org/10.1016/0550-3213(80)90434-4.

89. E.g., Peter Woit, Not Even Wrong: The Failure of String Theory and the Search for Unity in Physical Law (Basic Books, 2006).

90. In a way this project is a metaphorical meta-implementation of the ontic structural realist program in philosophy of science (Roman Frigg and Ioannis Votsis, "Everything You Always Wanted to Know about Structural Realism but Were Afraid to Ask," European Journal for Philosophy of Science 1.2 (May 1, 2011): 227-276. https://doi.org/10.1007/s13194-0110025-7).

\section{References}

Aiton, E. J. “Celestial Spheres and Circles.” History of Science 19.2 (June 1981): 75-114. https://doi.org/10.1177/007327538101900201

Aristotle. Meteorologica. Edited by Francis Howard Forbes. Cambridge, MA: Harvard University Press, 1919. http://archive.org/details/aristotelismeteo00arisuoft.

Aristotle. On Coming-to-Be and Passing-Away (De Generatione et Corruptione). Edited by Harold H. Joachim. Oxford: Clarendon Press, 1922. http://archive.org/details/ oncomingtobepass00arisuoft.

Aristotle. Metaphysics. Edited by William David Ross. Vol. 2. 2 vols. London: Clarendon Press, 1924.

Aristotle. Physics. Edited by David Ross. Oxford: Clarendon Press, 1936. 
Aristotle. Physica. Edited by David Ross. Oxford Classical Texts. Oxford ; New York: Oxford University Press, 1950.

Aristotle. De Caelo. Edited by D. J. Allan. Oxford Classical Texts. Oxford: Clarendon Press, 1961.

Aristotle. "Metaphysics." In Complete Works of Aristotle, edited by Jonathan Barnes, translated by W. D. Ross, Vol. 2. Bollingen 61. Princeton, NJ: Princeton University Press, 1984.

Aristotle. "Meteorology." In Complete Works of Aristotle, edited by Jonathan Barnes, translated by E. W. Webster, Vol. 1. Bollingen 61. Princeton, NJ: Princeton University Press, 1984.

Aristotle. "On Generation and Corruption." In Complete Works of Aristotle, edited by Jonathan Barnes, translated by H. H. Joachim, Vol. 1. Bollingen 61. Princeton, NJ: Princeton University Press, 1984.

Aristotle. "On the Heavens." In Complete Works of Aristotle, edited by Jonathan Barnes, translated by J. L. Stocks, Vol. 1. Bollingen 61. Princeton, NJ: Princeton University Press, 1984.

Aristotle. "Physics." In Complete Works of Aristotle, edited by Jonathan Barnes, translated by R. P. Hardie and R. K. Gaye, Vol. 1. Bollingen 61. Princeton, NJ: Princeton University Press, 1984.

Bostock, David. Space, Time, Matter, and Form: Essays on Aristotle's Physics. Oxford: Oxford University Press, 2006. http://www.oxfordscholarship.com/view/10.1093 /0199286868.001.0001/acprof-9780199286867.

Brodsky, Stanley J., and Sidney D. Drell. "Anomalous Magnetic Moment and Limits on Fermion Substructure.” Physical Review D 22.9 (November 1, 1980): 2236-2243. https://doi.org/10.1103/PhysRevD.22.2236

Brungardt, John. "The Principle of Least Action and Our Knowledge of Nature." Santiago, Chile, 2018. https://johngbrungardt.com/2018/11/30/the-principleof-least-action-chile/.

Chalmers, Alan. "Galilean Relativity and Galileo's Relativity.” In Correspondence, Invariance and Heuristics, edited by Steven French and Harmke Kamminga, 189-205. Boston Studies in the Philosophy of Science 148. Dordrecht: Springer, 1993. https://doi.org/10.1007/978-94-017-1185-2_10

Clarkson, Chris, Bruce Bassett, and Teresa Hui-Ching Lu. "A General Test of the Copernican Principle.” Physical Review Letters 101.1 (July 2, 2008): 011301. https://doi.org/10.1103/PhysRevLett.101.011301

Coughlin, Glen. “Appendix 10. A Brief Note on Inertia.” In Physics, or Natural Hearing, by Aristotle, 274-277, translated by Glen Coughlin. South Bend, IN: St. Augustine's Press, 2004.

Coughlin, Glen. "Some Considerations on Aristotelian Place and Newtonian Space." The Aquinas Review 1.1 (2003): 1-53.

Curiel, Erik. "On the Existence of Spacetime Structure." The British Journal for the Philosophy of Science 69.2 (June 1, 2018): 447-483. https://doi.org/10.1093/bjps/axw014 
De Groot, Jean. Aristotle's Empiricism: Experience and Mechanics in the Fourth Century BC. Las Vegas: Parmenides Publishing, 2014.

Decaen, Christopher A. "Aristotle's Aether and Contemporary Science." The Thomist 68.3 (2004): 375-429. https://doi.org/10.1353/tho.2004.0015

Eisele, Ch, A. Yu Nevsky, and S. Schiller. "Laboratory Test of the Isotropy of Light Propagation at the 10-17 Level.” Physical Review Letters 103. 9 (2009): 090401. https://doi.org/10.1103/PhysRevLett.103.090401

Feser, Edward. "The Medieval Principle of Motion and the Modern Principle of Inertia." In Proceedings of the Society for Medieval Logic and Metaphysics, 2012.

Feynman, Richard P., Robert B. Leighton, and Matthew Sands. The Feynman Lectures on Physics: Mainly Electromagnetism and Matter. New Millennium Ed. Vol. 2. 3 vols. Basic Books, 2015.

Feynman, Richard P., Robert B. Leighton, and Matthew Sands. The Feynman Lectures on Physics: Mainly Mechanics, Radiation, and Heat. New Millennium Ed. Vol. 1. 3 vols. Basic Books, 2015.

Frigg, Roman, and Ioannis Votsis. "Everything You Always Wanted to Know about Structural Realism but Were Afraid to Ask." European Journal for Philosophy of Science 1.2 (May 1, 2011): 227-276. https://doi.org/10.1007/s13194-011-0025-7

Goldman, T., and D. A. Ross. "Mass Scales for Grand Unified Theories: Are There Testable Alternatives to SU(5)?” Nuclear Physics B 162.1 (January 7, 1980): 102-114. https://doi.org/10.1016/0550-3213(80)90434-4

Hanany, Shaul, P. Ade, A. Balbi, J. Bock, J. Borrill, A. Boscaleri, P. De Bernardis, et al. "MAXIMA-1: A Measurement of the Cosmic Microwave Background Anisotropy on Angular Scales of 10'-5.” The Astrophysical Journal Letters 545.1 (2000): L5.

Hanc, Jozef, Slavomir Tuleja, and Martina Hancova. "Symmetries and Conservation Laws: Consequences of Noether's Theorem." American Journal of Physics 72.4 (March 10, 2004): 428-435. https://doi.org/10.1119/1.1591764

Hankinson, R. J. "Natural, Unnatural, And Preternatural Motions: Contrariety And The Argument For The Elements In De Caelo 1.2-4." In New Perspectives on Aristotle's De Caelo, edited by Alan Bowen and Christian Wildberg, 83-118. Philosophia Antiqua 117, 2009. http://booksandjournals.brillonline.com/content/books/10.1163/ ej.9789004173767.i-326.42/.

Hoskin, Michael. The Cambridge Concise History of Astronomy. Cambridge: Cambridge University Press, 1999.

Kosyakov, Boris. Introduction to the Classical Theory of Particles and Fields. Berlin: Springer, 2007.

Koyre, Alexandre. "Galileo and the Scientific Revolution of the Seventeenth Century." The Philosophical Review 52.4 (July 1943): 333. https://doi.org/10.2307/2180668

Krizan, Mary. "Elemental Structure and the Transformation of the Elements in On Generation and Corruption 2.4." Oxford Studies in Ancient Philosophy 45 (2013): 195. https://doi.org/10.1093/acprof:oso/9780199679430.003.0006 
Linde, A. D. "A New Inflationary Universe Scenario: A Possible Solution of the Horizon, Flatness, Homogeneity, Isotropy and Primordial Monopole Problems." Physics Letters B 108.6 (February 4, 1982): 389-393. https://doi.org/10.1016/0370-2693(82)91219-9

Machamer, Peter K. "Aristotle on Natural Place and Natural Motion." Isis 69.3 (September 1, 1978): 377-387. https://doi.org/10.1086/352066

Matthen, Mohan. "Why Does Earth Move to the Center? An Examination of Some Explanatory Strategies in Aristotle's Cosmology." In New Perspectives on Aristotle's De Caelo, edited by Alan Bowen and Christian Wildberg, 119-38. Philosophia Antiqua 117, 2009. http://booksandjournals.brillonline.com/content/books/10.1163/ ej.9789004173767.i-326.42/.

Maudlin, Tim. Quantum Non-Locality and Relativity: Metaphysical Intimations of Modern Physics. 3rd ed. Malden, MA: Wiley-Blackwell, 2011.

Maudlin, Tim. "Substances and Space-Time: What Aristotle Would Have Said to Einstein." Studies in History and Philosophy of Science Part A 21. 4 (December 1990): 531-561. https://doi.org/10.1016/0039-3681(90)90032-4

McLaughlin, Thomas. "Local Motion and the Principle of Inertia: Aquinas, Newtonian Physics, and Relativity." International Philosophical Quarterly 44.2 (2004): 239-264. https://doi.org/10.5840/ipq20044426

McLaughlin, Thomas J. "Nature and Inertia." The Review of Metaphysics 62.2 (May 1, 2008): 251-284.

McMahon, David. Quantum Field Theory Demystified. McGraw Hill Professional, 2008.

Moreno, Antonio. "The Law of Inertia and the Principle Quidquid movetur ab alio movetur." The Thomist 38 (April 1974): 306-331.

Moreno, Antonio. "Time and Relativity: Some Philosophical Considerations." The Thomist 45.1 (1981): 62-79. https://doi.org/10.1353/tho.1981.0044

Nadis, Steve. "The Universe According to Emmy Noether." Discover, June 12, 2017. http://discovermagazine.com/2017/june/the-universe-according-to-emmy-noether.

Noether, Emmy. "Invariante Variationsprobleme." Nachrichten von der Gesellschaft der Wissenschaften zu Göttingen, Mathematisch-Physikalische Klasse, 235-257. Berlin: Weidmannssche-Buchbandlung, 1918.

Rosen, Edward. "The Dissolution of the Solid Celestial Spheres." Journal of the History of Ideas 46.1 (January 1985): 13. https://doi.org/10.2307/2709773

Smith, Crosbie, and M. Norton Wise. Energy and Empire: A Biographical Study of Lord Kelvin. Cambridge: Cambridge University Press, 1989.

Stenger, Victor J. The Comprehensible Cosmos: Where Do the Laws of Physics Come From? Prometheus Books, 2006.

Swanson, Mark S. Classical Field Theory and the Stress-Energy Tensor. San Rafael, CA: Morgan and Claypool Publishers, 2015. 
Wallace, William Augustine. Galileo's Logic of Discovery and Proof: The Background, Content, and Use of His Appropriated Treatises on Aristotle's Posterior Analytics. Boston Studies in the Philosophy of Science 137. Dordrecht: Springer, 1992. http://link. springer.com/10.1007/978-94-015-8040-3.

Woit, Peter. Not Even Wrong: The Failure of String Theory and the Search for Unity in Physical Law. Basic Books, 2006. 